\title{
EFEKTIVITAS FORMULASI BIOHERBISIDA EKSTRAK BUAH LERAK DENGAN PENAMBAHAN ADJUVAN TERHADAP PERKECAMBAHAN GULMA Ludwigia octovalvis
}

\author{
Effectivity of Bioherbicide Formulation of \\ Sapindus rarak Fruit plus Adjuvan \\ on Seed Germination of Ludwigia octavalvis
}

\author{
Hidayat Pujisiswanto*, Sunyoto, Nanik Sriyani, dan Melynda Tri Pratiwi \\ Jurusan Agronomi dan Hortikultura, Fakultas Pertanian Universitas Lampung \\ *E-mail: hidayat.pujisiswantof@fp.unila.ac.id
}

\begin{abstract}
ABSTRAK
Banyaknya gulma di lahan budidaya dapat secara langsung menghambat pertumbuhan tanaman melalui kompetisi sarana tumbuh. Pengendalian gulma menggunakan bioherbisida merupakan salah satu alternatif budidaya pertanaian yang ramah lingkungan. Penelitian ini bertujuan untuk mengetahui formulasi bioherbisida ekstrak buah lerak (Sapindus rarak) dengan penambahan adjuvan yang dapat menghambat perkecambahan gulma Ludwigia octovalvis. Penelitian dilaksanakan di Laboratorium Gulma Fakultas Pertanian Universitas Lampung pada bulan Desember 2019 - Maret 2020. Penelitian menggunakan Rancangan Acak Lengkap (RAL). Perlakuan penelitian terdiri dari: ekstrak buah lerak + adjuvan KAO, ekstrak buah lerak + VCO, ekstrak buah lerak + Tween, ekstrak buah lerak murni, dan kontrol (aquades), setiap perlakuan diulang 4 kali. Hasil penelitian menunjukkan bahwa aplikasi ekstrak buah lerak 50\% (500 g/l) dengan penambahan adjuvan VCO, KAO, dan Tween pada konsentrasi $2 \%$ (20 ml/l) mampu menghambat perkecambahan biji gulma Ludwigia octovalvis sebesar $98 \%$ - 99\%. Aplikasi ekstrak buah lerak dengan penambahan adjuvan VCO $2 \%$ sama efektif dibanding penambahan KAO dan Tween dalam menghambat perkecambahan biji gulma Ludwigia octovalvis.
\end{abstract}

Kata kunci : adjuvan, bioherbisida, buah lerak, gulma, Ludwigia octovalvis,

\section{ABSTRACT}

The abundance of weeds in cultivated land can directly inhibit competition of plants growth. Weed control using bioherbicides is one of eco-friendly alternative. This research aimed to determine the bioherbicide formulation of lerak fruit extract with the addition of adjuvants which can inhibit the germination of Ludwigia octovalvis. The research was conducted at the Weed Laboratory of the Faculty of Agriculture, University of Lampung in December 2019 - March 2020. The researcher used Complete Randomized Design (CRD) with four replications. The research treatments consisted of lerak fruit extract $+K A O$ adjuvant, lerak fruit extract $+V C O$, lerak fruit extract + Tween, pure lerak fruit extract, and control (aquades). The results showed that the application of $50 \%(500 \mathrm{~g} / \mathrm{l})$ lerak fruit extract with the addition of VCO, KAO, and Tween adjuvants at a concentration of $2 \%(20 \mathrm{ml} / \mathrm{l})$ was able to inhibit seed germination of Ludwigia octovalvis by $95 \%-100 \%$. The application of lerak fruit extract with the addition of 2\% VCO adjuvant was as effective as additional of KAO and Tween in inhibiting seed germination of Ludwigia octovalvis.

Keywords : adjuvants, Bioherbicide, Sapindus rarak, Ludwigia octovalvis, weed 


\section{PENDAHULUAN}

Gulma merupakan tumbuhan yang sering kali tumbuh pada tempat, kondisi dan waktu yang tidak diinginkan dan dapat mengganggu atau merugikan kepentingan manusia, sehingga perlu dikendalikan. Salah satu gulma penting yang mengganggu pertanaman padi sawah yaitu Ludwigia octovalvis (Ahn dan Chung, 2000). Gulma tersebut dapat menghambat pertumbuhan dan menekan produksi tanaman padi sawah. Menurut Hooper et al. (2010) penurunan hasil padi yang ditimbulkan akibat keberadaan gulma ini sekitar $10-15 \%$. Gulma lakum air (Ludwigia octovalvis) juga merupakan gulma tahunan yang berbunga sepanjang tahun sehingga produksi biji dapat berlangsung terus-menerus. Oleh karena itu, perlu dilakukan pengendalian secara tepat dalam mengendalikan gulma tersebut. Salah satu cara yang sering dilakukan untuk mengendalikan gulma yaitu dengan dilakukan pengendalian secara kimiawi. Penggunaan herbisida kimia sintetis yang terus-menerus akan menyebabkan terjadinya resiko pencemaran lingkungan akibat residu bahan aktif herbisida. Solusi yang dapat dilakukan untuk menekan penggunaan herbisida kimia sintetis yaitu dengan menggunakan bioherbisida.

Herbisida nabati merupakan herbisida yang memanfaatkan senyawa alelokimia yang terkandung dalam organ-organ tumbuhan, senyawa alelokimia tersebut diduga mampu mengendalikan gulma atau tumbuhan pengganggu (Senjaya dan Surakusumah, 2007). Senyawa - senyawa alelokimia tersebut bersifat ramah lingkungan. Salah satu tanaman yang memiliki kandungan senyawa alelokimia yaitu Lerak (Sapindus rarak DC). Menurut Widowati (2003), semua bagian tanaman lerak memiliki kandungan saponin dan kandungan saponin tertinggi terdapat pada buahnya. Menurut Wina et al. (2005), buah lerak, terdapat beberapa senyawa alelopati yaitu senyawa alkaloid, fenol, saponin, terpenoid, asam lemak, sterois, dan polycetylene. Senyawa- senyawa tersebut diduga mampu menghambat pertumbuhan gulma dan dapat dijadikan sebagai herbisida nabati. Untuk meningkatkan daya efektivitas dari herbisida nabati ekstrak buah lerak tersebut perlu ditambahkan adjuvan. Sehingga pada penelitian ini menambahkan adjuvan pada aplikasi ekstrak buah lerak untuk meningkatkan daya rekat dan efikasi herbisida nabati ekstrak buah lerak dalam mengendalikan gulma Ludwigia octovalvis.

Bahan tambahan (adjuvant) merupakan bahan atau senyawa yang ditambahkan dalam proses formulasi agar herbisida mudah untuk diaplikasikan. Adjuvan berfungsi sebagai penguat daya penetrasi bahan aktif herbisida ke tanaman, sehingga penggunaan herbisida lebih efisien dan tepat guna untuk semua herbisida baik sistemik maupun kontak. Penambahan bahan tambahan ini akan dapat meningkatkan daya efikasi lerak. Penggunaan adjuvan (surfaktan) yang mengandung minyak dengan konsentrasi 1$2 \%$ dapat meningkatkan penyerapan herbisida melalui jaringan tanaman dan meningkatkan retensi semprotan (Hazen, 2000). Oleh karena itu, penelitian ini dilakukan untuk mengetahui efektivitas formulasi bioherbisida ekstrak buah lerak dengan penambahan adjuvan yang dapat menghambat perkecambahan gulma Ludwigia octovalvis.

\section{METODE PENELITIAN}

Penelitian ini dilaksanakan di Laboratorium Gulma Fakultas Pertanian Universitas Lampung pada bulan Desember 2019 - Maret 2020. Bahan yang digunakan yaitu 50\% (500 g/l) ekstrak buah lerak, adjuvan Tween, adjuvan KAO, adjuvan VCO (Virgin Coconut Oil), biji gulma Ludwigia octovalvis, kertas merang, spons, plastik wrapping, aquades, dan label. Alat yang digunakan adalah cawan petri, timbangan digital, gelas ukur, sprayer, ruber $b u l b$, pipet, oven, dan gunting. 
Rancangan yang digunakan pada uji perkecambahan biji gulma Ludwigia octovalvis menggunakan Rancangan Acak Lengkap (RAL) faktorial tunggal. Perlakuan terdiri dari 5 jenis perlakuan yaitu ekstrak buah lerak $(50 \% \mathrm{w} / \mathrm{v})+$ adjuvan KAO $(2 \%$ $\mathrm{v} / \mathrm{v})$, ekstrak buah lerak $(50 \%)+\mathrm{VCO}(2 \%$ $\mathrm{v} / \mathrm{v})$, ekstrak buah lerak $(50 \%+$ Tween $(2 \%$ $\mathrm{v} / \mathrm{v})$, ekstrak buah lerak murni (50\%), dan kontrol (aquades). Perlakuan diulang 4 kali. Homogenitas ragam data diuji dengan uji Barlett. Jika asumsi terpenuhi, analisis data akan dilanjutkan dengan analisis ragam dan uji Beda Nyata Terkecil (BNT) pada taraf nyata $5 \%$ digunakan untuk menguji perbedaan nilai tengah.

Uji perkecambahan benih dilakukan menggunakan cawan petri berukuran $10 \mathrm{~cm}$ x $5 \mathrm{~cm}$ yang telah dimasukan media tanam berupa spons dan kertas merang. Pada setiap cawan petri dilakukan penyemaian biji gulma Ludwigia octovalvis sebanyak 100 biji, kemudian disemprot dengan $5 \mathrm{ml}$ larutan ekstrak buah lerak sesuai dengan perlakuan yang telah ditentukan. Variabel yang diamati pada uji perkecambahan yaitu daya berkecambah dan kecepatan perkecambahan. Pengamatan dilakukan selama 2 minggu dan pengamatan dilakukan setiap hari.

\section{HASIL DAN PEMBAHASAN}

Hasil penelitian yang telah dilakukan menunjukkan bahwa aplikasi ekstrak buah lerak dengan penambahan adjuvan berpengaruh nyata terhadap presentase perkecambahan, dan kecepatan perkecambahan.

\section{Persentase Perkecambahan Gulma}

Hasil penelitian uji perkecambahan yang dilakukan pada 1 dan 2 MSA menunjukkan aplikasi ekstrak buah lerak dengan penambahan adjuvan $\mathrm{KAO}, \mathrm{VCO}$, dan Tween (masing-masing 2\%) atau tanpa adanya penambahan adjuvan dapat menghambat perkecambahan gulma Ludwigia octovalvis (Tabel 1). Hal ini diduga bahwa ekstrak buah lerak dapat berpotensi sebagai bioherbisida pratumbuh pada gulma Ludwigia octovalvis. Terjadinya penghambatan perkecambahan pada biji gulma diduga adanya senyawa alelokimia yang terkandung dalam ekstrak buah lerak, serta adanya penambahan adjuvan yang berfungsi sebagai penambah efektivitas dari ekstrak buah lerak.

Menurut Fatmawati (2014), buah lerak mengandung senyawa alelokimia berupa saponin, flavonoid, fenol, polifenol, dan tanin. Senyawa alelokimia tersebut dapat merusak jaringan embrio biji sehingga menyebabkan biji mati atau terhambat untuk berkecambah (Macias et al., 2004). Menurut Rahayu (2003), mekanisme pengaruh alelopati dalam menghambat pertumbuhan dan perkembangan tumbuhan lain yaitu diawali dengan terganggungnya sistem pada membran plasma dengan cara merusak struktur membran, memodifikasi saluran membran, atau hilangnya fungsi enzim ATP-ase.

Pada pengamatan 2 MSA menunjukkan bahwa pengaplikasian ekstrak buah lerak dengan penambahan adjuvan (VCO, KAO, dan Tween) atau tanpa adanya penambahan adjuvan (ekstrak buah lerak murni) masih menghambat perkecambahan biji gulma L. Octovalvis. Hal ini dapat dilihat dari media tanam yang berwarna hitam kecoklatan yang merupakan sisa dari pengaplikasian ekstrak buah lerak (Gambar 1). Sedangkan biji gulma L. octovalvis yang diberi perlakuan aquades (kontrol) mampu berkecambah hingga 68,61 \%. Hal ini disebabkan karena buah lerak mengandung senyawa saponin sekitar $48,47 \%$, senyawa tersebut yang diduga merupakan senyawa racun yang dapat menekan pertumbuhan gulma (Sunaryadi, 1999). 
Tabel 1. Pengaruh ekstrak buah lerak terhadap persentase perkecambahan biji gulma Ludwigia octovalvis.

\begin{tabular}{lcccc}
\hline \multirow{2}{*}{ Perlakuan } & \multicolumn{2}{c}{ 1 MSA } & \multicolumn{2}{c}{ 2 MSA } \\
\cline { 2 - 5 } & Asli & (Arcsin $\sqrt{\mathrm{x}})$ & Asli & $($ Arcsin $\sqrt{\mathrm{x}})$ \\
\hline Aquades (Kontrol) & 67,50 & $55,39 \mathrm{a}$ & 79,75 & $63,61 \mathrm{a}$ \\
Ekstrak lerak + VCO & 0,50 & $2,87 \mathrm{~b}$ & 0,50 & $2,87 \mathrm{~b}$ \\
Ekstrak lerak +KAO & 0,00 & $0,00 \mathrm{~b}$ & 0,25 & $1,43 \mathrm{~b}$ \\
Ekstrak lerak + Tween & 0,50 & $2,87 \mathrm{~b}$ & 0,50 & $2,87 \mathrm{~b}$ \\
Ekstrak lerak murni & 1,25 & $4,32 \mathrm{~b}$ & 1,50 & $5,75 \mathrm{~b}$ \\
\hline \multicolumn{1}{c}{ BNT 5\% } & \multicolumn{5}{c}{6,26} & 6,47 \\
\hline
\end{tabular}

Keterangan : Nilai rata-rata yang diikuti oleh huruf yang sama dalam kolom yang sama tidak berbeda nyata pada BNT 5\%
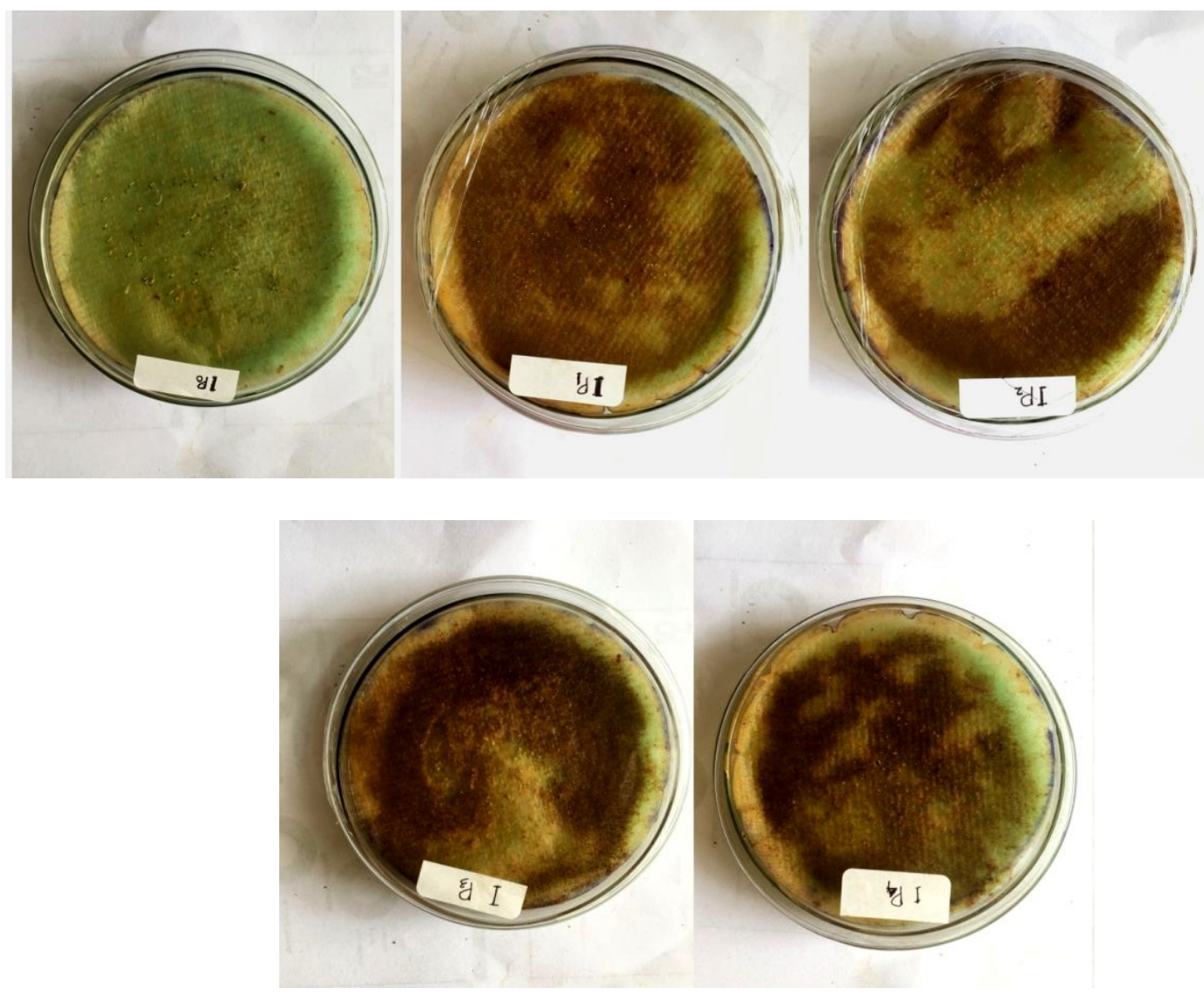

Gambar 1. Pengaruh ekstrak buah lerak dengan penambahan adjuvan pada perkecambahan biji gulma Ludwigia octovalvis. 
Tabel 2. Pengaruh ekstrak buah lerak terhadap kecepatan perkecambahan biji gulma Ludwigia octovalvis

\begin{tabular}{|c|c|c|}
\hline \multirow[b]{2}{*}{ Perlakuan } & \multicolumn{2}{|c|}{ Kecepatan Perkecambahan } \\
\hline & Asli & $(\operatorname{Arcsin} \sqrt{ } x)$ \\
\hline & & ----------- \\
\hline Aquades (Kontrol) & 27,75 & $31,73 \mathrm{a}$ \\
\hline Ekstrak lerak + VCO & 0,09 & $1,18 \quad b$ \\
\hline Ekstrak lerak +KAO & 0,02 & $0,43 \mathrm{~b}$ \\
\hline Ekstrak lerak + Tween & 0,07 & $1,07 \quad b$ \\
\hline Ekstrak lerak murni & 0,23 & $2,53 \mathrm{~b}$ \\
\hline BNT 5\% & & 2,38 \\
\hline
\end{tabular}

Keterangan : Nilai rata-rata yang diikuti oleh huruf yang sama dalam kolom yang sama tidak berbeda nyata pada BNT $5 \%$

Hasil penelitian (Tabel 2) menunjukkan ekstrak buah lerak menghasilkan kecepatan perkecambahan biji gulma L.octovalvis lebih rendah dibandingkan tanpa penambahan adjuvan. Hal ini disebabkan karena adanya penambahan adjuvan dapat meningkatkatkan daya efikasi herbisida nabati ekstrak buah lerak tersebut. Menurut Hazen (2000), penggunaan adjuvan (surfaktan) yang mengandung minyak dengan konsentrasi $1-2 \quad \%$ dapat meningkatkan penyerapan herbisida melalui jaringan tanaman dan meningkatkan retensi semprotan. Sehingga pada penelitian ini pengaplikasian ekstrak buah lerak dengan penambahan adjuvan dinilai lebih efektif dalam menghambat perkecambahan biji gulma.

\section{KESIMPULAN}

Pengaplikasian bioherbisida ekstrak buah lerak konsentrasi $50 \% \quad(500 \mathrm{~g} / \mathrm{l})$ dengan penambahan adjuvan VCO, KAO, dan Tween pada konsentrasi $2 \%(20 \mathrm{ml} / \mathrm{l})$ mampu menghambat perkecambahan gulma Ludwigia octovalvis sebesar 98\%-99\%. Sedangkan pengaplikasian ekstrak buah lerak dengan penambahan adjuvan VCO konsentrasi $2 \%$ sama efektif dengan penambahan KAO dan Tween dalam menghambat perkecambahan gulma Ludwigia octovalvis.

\section{DAFTAR PUSTAKA}

Ahn, J.K and I.M. Chung. 2000.Allelophatic Potential of Rice Hullon Germination and Seedling Growth of Barnyardgrass. Agronomy Journal. 92 : 1162-1167.

Fatmawati, I. 2014. Efektivitas Buah Lerak (Sapindus rarak De Candole) sebagai Bahan Pembersih Logam Perak, Perunggu, dan Besi. Jurnal Konservasi Cagar Budaya Borobudur, 8(2) : 24-31.

Hazen, J.L. 2000. Adjuvants - Terminology, Classification, and Chemistry.Weed Technology, 14:773-784.

Hooper, A., Tsanuo, M.K., Chamberlain, K., Tittcomb, K., Scholes, J., Khan, Z.R., and Pickett, J.A. 2010. Isoschaftoside, a $C$-glycosyl flavonoid from Desmodiumun cinatum Root Exudate, is an Allelechemical Against the Development of Striga. Phytochemistry. 71(8-9):904-908.

Macias, F.A., Galindo, J.C.G., Molinillo, J.M.G. and Cutler, H.G. 2004. Allelopathy: Chemistry and Mode of Action of Allelochemicals. CRC Press. New York.

Rahayu, E. S. 2003. Peranan Penelitian Alelopati dalam Pelaksanaan Low External Input 
and Sustainabel Agriculture (LEISA). Institut Pertanian Bogor. Bogor.

Senjaya, Y.A., dan W. Surakusumah. 2007.Potensi ekstrak daun pinus (Pinus merkusii) sebagai bioherbisida penghambat perkecambahan Echinochloa colonum dan Amaranthus viridis. Jurnal Perennial, 4(1):1-5.

Sunaryadi. 1999. Ekstraksi dan isolasi buah lerak (Sapindus rarak) serta pengujian daya defaunasinya. Tesis. Program Pascasarjana Institut Pertanian Bogor. Bogor.
Widowati, L. 2003. Sapindus rarak DC. In: Lemmens RHMJ. Bunyapraphastsara, N. (Eds). Plant Resources of South-East Asia. Medicinal and Poisonous Plants. Prosea Foundation. Bogor. 12 (3): 358359.

Wina, E., S. Muetzel., E.M. Hoffmann., H.P.S. Makkar., and K. Becker. 2005. Saponin containing methanol extract of Sapindus rarak affect microbial fermentation, microbial activity and microbial community structure in vitro. Anim. Feed. Sci. Technol., 121: 59-174. 